\title{
Protective and therapeutic effects of pyrrolidine dithiocarbamate in a rat tongue cancer model created experimentally using 4-nitroquinoline 1-oxide
}

\author{
Aysenur Meric HaffI ${ }^{1, A}$, Remzi Doğann ${ }^{2, A, B, D}$, Zuhal Gucinn ${ }^{3, B, C}$, Omer Faruk Ozef ${ }^{A, B, C}$, Alper Yenigun ${ }^{2, E}$, Orhan Ozturan ${ }^{2, F}$ \\ ${ }^{1}$ Department of Otorhinolaryngology, Koc University, Istanbul, Turkey \\ ${ }^{2}$ Department of Otorhinolaryngology, Bezmialem Vakif University, Istanbul, Turkey \\ ${ }^{3}$ Department of Pathology, Bezmialem Vakif University, Istanbul, Turkey \\ ${ }^{4}$ Department of Biochemistry, Bezmialem Vakif University, Istanbul, Turkey \\ A - research concept and design; B - collection and/or assembly of data; C - data analysis and interpretation; \\ $D$ - writing the article; $E$ - critical revision of the article; $F$ - final approval of the article
}

Address for correspondence

Remzi Doğan

E-mail:dr.remzidogan@gmail.com

\section{Funding sources}

None declared

Conflict of interest

None declared

Received on November 3, 2019

Reviewed on June 13, 2020

Accepted on September 20, 2020

\section{Cite as}

Hafız AM, Doğan R, Gucin Z, Ozer OF, Yenigun A, Ozturan 0. Protective and therapeutic effects of pyrrolidine dithiocarbamate in a rat tongue cancer model created experimentally using 4-nitroquinoline 1-oxide. Adv Clin Exp Med. 2020;29(11):1249-1254. doi:10.17219/acem/127682

DOI

10.17219/acem/127682

\section{Copyright}

Copyright by Author(s)

This is an article distributed under the terms of the

Creative Commons Attribution 3.0 Unported (CC BY 3.0)

(https://creativecommons.org/licenses/by/3.0/)

\begin{abstract}
Background. Tongue tumors, which are oropharyngeal tumors, are increasing in frequency. Pyrrolidine dithiocarbamate (PDTC) is a powerful antioxidant and antitumoral agent.

Objectives. To evaluate the protective and therapeutic effects of PDTC in a tongue cancer model induced with 4-nitroquinoline 1-oxide (4-NQO).

Material and methods. We included 40 rats in the trial and assigned them randomly to 5 groups. Group 1 (cancer, $n=7)$ : 4-NQO (0-12 weeks); group 2 (protection, $n=8)$ : 4-NQO (0-12 weeks) + PDTC ( $300 \mathrm{mg} /$ $\mathrm{kg} / \mathrm{day}, 0-12$ weeks); group 3 (therapy-high dose, $\mathrm{n}=10)$ ) 4-NQ0 (0-12 weeks) + PDTC (600 mg/kg/day, weeks 12-30); group 4 (therapy-low dose, $n=10)$ : 4-NQO (0-12 weeks) + PDTC (300 mg/kg/day, weeks 12-30); and group 5 (control). Cardiac blood samples were taken to analyze oxidative stress parameters (total antioxidant status (TAS), total oxidant status (TOS) and oxidative stress index (OSI)). Histopathological assessment was performed under a light microscope.
\end{abstract}

Results. The results of the histopathological assessment showed that the model we used in group 1 was successful, which was consistent with the literature. The PDTC dose administered in group 2 could not prevent tumor formation. Group 3 demonstrated that PDTC in high doses is effective as a therapeutic agent. Group 4 indicated that PDTC in low doses has no therapeutic effect. The results of the biochemical assessment showed that in group 3, TOS and OSI values were significantly lower than in groups 1, 2 and 4 . No significant difference was found in the TOS and OSI values between groups 5 and 3.

Conclusions. Our study demonstrated histopathologically that in an experimentally generated tongue cancer model, application of $600 \mathrm{mg} / \mathrm{kg} / \mathrm{day}$ of PDTC led to a significant reduction in the size of the tumor. This was supported by the biochemical parameters.

Key words: antioxidant, tongue cancer, antitumoral, pyrrolidine dithiocarbamate, 4-nitroquinoline 1-oxide 


\section{Introduction}

Oral and parapharyngeal cancer represents less than $2 \%$ of all deaths from cancer and more than $2 \%$ of newly diagnosed cancer cases. ${ }^{1}$ The progression of oral cancer proceeds from hyperplastic epithelial lesions to dysplasia and invasive carcinoma. ${ }^{2}$ Remission and prognosis are linked to a more detailed understanding of the multi-stage process causing the development of cancer. ${ }^{3}$ It is therefore important to repress the carcinogenesis with chemoprotective agents. Many current studies are directed towards identifying currently available chemoprotective agents. ${ }^{4}$ Some of these agents are foodstuffs such as vegetables and fruit, and it has been reported that they act as protective agents in carcinoma of the tongue. ${ }^{5}$ These chemoprotective agents have anti-proliferative, anti-inflammatory and antioxidant effects.

Pyrrolidine dithiocarbamate (PDTC) is a metal chelator and antioxidant as well as nuclear factor kappa-light-chainenhancer of activated B cells (NF-kB) inhibitor. It is a thiol compound of low molecular weight. It has a large number of biological activities, including changing the redox state, ${ }^{6}$ chelating heavy metal ions ${ }^{7}$ and inhibiting enzymes. ${ }^{8}$ Principally, PDTC is a powerful inhibitor of NF- $\mathrm{kB} .{ }^{9}$ It shows an antioxidant effect, preventing the toxic effect of free radicals ${ }^{10}$ as well as blocking the pro-inflammatory effects of cytokines. ${ }^{11}$ In addition, it increases antioxidant activity by increasing the gene expression of superoxide dismutase $(\mathrm{SOD})^{12}$ and glutathione peroxidase (GPX), ${ }^{13} 2$ endogenase antioxidant enzymes. In addition, PDTC affects oxidantrelated cell damage by reducing the build-up of malondialdehyde (MDA). ${ }^{14}$ Studies have shown that PDTC, particularly through NF-kB inhibition, prevents the development, growth and angiogenesis of tumors. ${ }^{15,16} \mathrm{We}$ also studied the effectiveness of PDTC in preventing and treating experimentally produced tongue cancer.

\section{Material and methods}

\section{Animals, diets and chemicals}

Our study was started after obtaining approval from the Ethics Committee for experimental research at Bezmialem Vakif University (Istanbul, Turkey). We included 40 female Sprauge-Dawley rats (8 weeks old). All the animals were kept in cages in groups of 3 or 4, with drinking water and standard feed ad libitum. The day/night rhythm was set to $12 / 12 \mathrm{~h}$, and the temperature was $23^{\circ} \mathrm{C}$.

The animals were randomly assigned to 5 groups:

Group 1 (cancer, $\mathrm{n}=7$ ): 20 ppm of 4-nitroquinoline 1-oxide (4-NQO) was added to the drinking water for the first 12 weeks of the study.

Group 2 (protection, $\mathrm{n}=8$ ): 20 ppm of 4-NQO was added to the drinking water for the first 12 weeks of the study.
In addition, a dose of $300 \mathrm{mg} / \mathrm{kg} /$ day of PDTC was administered by gavage for the same 12-week period.

Group 3 (high-dose therapy, $\mathrm{n}=10$ ): $20 \mathrm{ppm}$ of 4-NQO was added to the drinking water for the first 12 weeks of the study. Subsequently, a dose of $600 \mathrm{mg} / \mathrm{kg} / \mathrm{day}$ of PDTC was given by gavage from week 13 until week 30 .

Group 4 (low-dose therapy, $\mathrm{n}=10$ ): $20 \mathrm{ppm}$ of 4-NQO was added to the drinking water for the first 12 weeks of the study. Subsequently, a dose of $300 \mathrm{mg} / \mathrm{kg} /$ day of PDTC was given by gavage from week 13 until week 30 .

Group 5 (control, $\mathrm{n}=5$ ): Physiological saline $\left(1 \mathrm{~cm}^{3}\right)$ was administered by gavage for 12 weeks.

Groups 1, 2 and 5 were sacrificed at the end of the $12^{\text {th }}$ week; groups 3 and 4 were sacrificed at the end of the $30^{\text {th }}$ week. After sacrificing the rats, their tongues were excised. Macroscopic photographs were taken.

\section{Histopathological analysis}

Each tongue was cut in half longitudinally. Each tissue specimen was fixed in $10 \%$ buffered formalin and embedded in paraffin blocks. Each specimen was sliced into multiple transverse sections for histological processing. The histopathological evaluation was performed by light microscopy. The tongue sections were graded as normal, hyperplasia, carcinoma in situ, dysplasia, or carcinoma per animal, as modified from the method described by Ribeiro et al. ${ }^{17}$

\section{Biochemical parameters}

At the end of the study, before sacrificing the rats, cardiac blood samples $(5 \mathrm{~mL})$ were taken to analyze oxidative stress parameters: total antioxidant status (TAS), total oxidant status (TOS) and oxidative stress index (OSI). The heparinized blood was centrifuged $(1500 \times \mathrm{g}$ for $10 \mathrm{~min})$ and the serum that was obtained was saved at $-80^{\circ} \mathrm{C}$ for TOS and TAS analysis using commercial kits (Rel Assay Diagnostics, Gaziantep, Turkey); the OSI was the TOS-to-TAS ratio (see below).

\section{Measurement of total oxidant status}

Plasma TOS was measured using an automated method developed by Erel. ${ }^{18}$ The oxidants present in a sample oxidize the ferrous ion in an o-dianisidine complex to ferric ion. Oxidation is enhanced using glycerol, which is abundant in the reaction medium, and the ferric ion forms a colored complex with xylenol orange under acidic conditions. The color intensity (which can be measured spectrophotometrically) is associated with the total level of oxidants present. Hydrogen peroxide is used to calibrate the assay, and the results are expressed in terms of micromoles of hydrogen peroxide equivalent per liter ( $\mathrm{mmol} \mathrm{H}_{2} \mathrm{O}_{2}$ equiv/L). 


\section{Measurement of total antioxidant status}

Plasma TAS was measured using another automated method developed by Erel. ${ }^{19}$ This involves production of the hydroxyl radical, which is a potent biological reactant. A ferrous ion solution (reagent 1 ) is mixed with hydrogen peroxide (reagent 2). Radicals produced by the hydroxyl radical, including the brown dianisidinyl radical cation, are also potent in biological terms. Thus, it is possible to measure the antioxidative capacity of a sample in terms of the inhibition of free radical reactions initiated by the production of the hydroxyl radical. Variation in the assay data is very low (less than $3 \%$ ), and results are expressed as mmol Trolox equiv/L.

\section{Measurement of oxidative stress index}

The OSI is the TOS-to-TAS ratio, but TAS values were changed to $\mathrm{mmol} / \mathrm{L}$. Each OSI was calculated as follows: OSI (arbitrary units) $=$ TOS $\left(\mathrm{mmol} \mathrm{H}_{2} \mathrm{O}_{2} / \mathrm{l}\right) / \mathrm{TAS}(\mathrm{mmol}$ Trolox/L). ${ }^{20}$

\section{Statistical analysis}

The statistical analysis was carried out using the Statistical Package for the Social Sciences v. 13.0 for Windows (SPSS Inc., Chicago, USA). All quantitative variables were assessed using measures of central location (i.e., mean and median) and measures of dispersion (i.e., standard deviation (SD)). Data normality was checked using the Kolmogorov-Smirnov test.

For inter-group comparisons, the one-way analysis of variance (ANOVA) was used. Tukey's honestly significant differences (HSD) post hoc test was used with the Bonferroni correction applied was used to establish between which groups a difference existed ( $\mathrm{p}<0.01$ was accepted as statistically significant). To assess qualitative data, the $\mathrm{X}^{2}$ test was used; $\mathrm{p}<0.05$ was accepted as significant.

\section{Results}

The rats were weighed at the beginning of the study and before sacrificing the animals (Table 1 ).

Table 1. Body mass of rats range before and after treatment

\begin{tabular}{|l|c|c|}
\hline \multicolumn{1}{|c|}{ Group } & Before $[\mathrm{g}]$ & After $[\mathrm{g}]$ \\
\hline Group $1(\mathrm{n}=7)$ cancer & $219.7 \pm 24.9$ & $165.2 \pm 17.3$ \\
\hline Group 2 $(n=8)$ protection & $228.5 \pm 23.9$ & $201.8 \pm 10.9$ \\
\hline Group 3 $(n=10)$ high-dose therapy & $219.1 \pm 27.5$ & $195.3 \pm 14.7$ \\
\hline Group 4 $(n=10)$ low-dose therapy & $226.8 \pm 20.3$ & $180.1 \pm 12.5$ \\
\hline Group 5 $(n=5)$ control & $216.3 \pm 25.8$ & $247.4 \pm 32.8$ \\
\hline
\end{tabular}

\section{Histopathological analysis}

Group 1 (4-NQO 12 weeks): Of the 7 rats used, after 12 weeks 4 had in situ squamous cell carcinomas (SCC), 2 had high-grade dysplasia and 1 had middle-grade dysplasia (Fig. 1). Group 2 (4-NQO weeks 0-12 + PDTC 300 mg/kg/day weeks $0-12)$ : Of the 8 rats used, after 12 weeks, 1 had superficial invasive SCC, 1 had in situ SCC, 1 had noninvasive SCC, 4 had high-grade dysplasia, and 1 had low-grade dysplasia (Fig. 2). Group 3 (4-NQO weeks 0-12 + PDTC 600 mg/ $\mathrm{kg}$ /day weeks 12-30): Of the 10 rats used, after 30 weeks, 1 had middle-grade dysplasia, 1 high-grade dysplasia and 5 had low-grade dysplasia, while 3 were healthy (Fig. 3). Group 4 (4-NQO weeks 0-12 + PDTC 300 mg/kg/day weeks 12-30): Of the 10 rats used, after 30 weeks, 4 had invasive SCC , 2 had superficial invasive SCC and 4 had non-invasive SCC (Fig. 4). Group 5 (physiological saline 12 weeks): None of the rats developed tumors (Fig. 5).

Our study found no significant difference between groups 1 and 2 in terms of carcinogenesis ( $p>0.05)$. Likewise, there was no significant difference between groups 3 and 5 ( $\mathrm{p}>0.05$ ). Significant differences in terms of carcinogenesis were found between groups 3 and $1(\mathrm{p}<0.05)$ and between groups 3 and $4(\mathrm{p}<0.05)$.

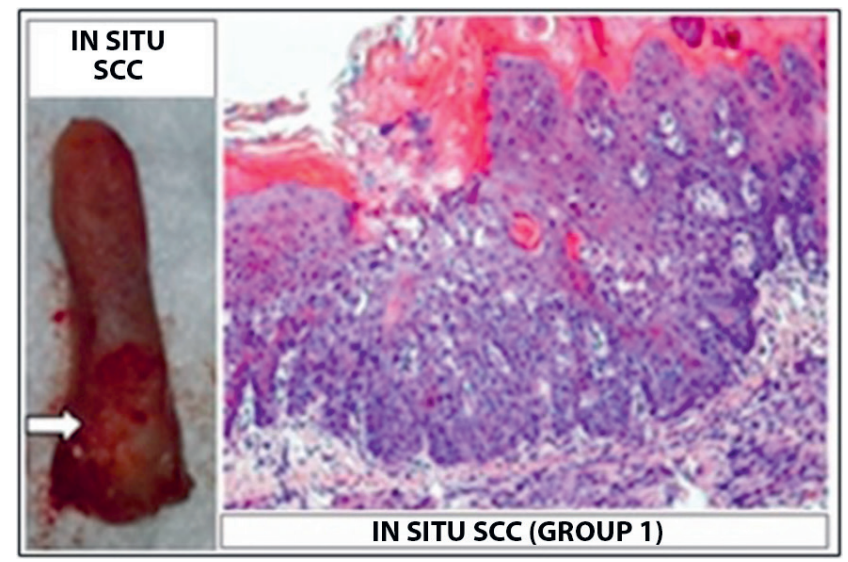

Fig. 1. Macroscopic and histopathological view of group 1 (cancer)

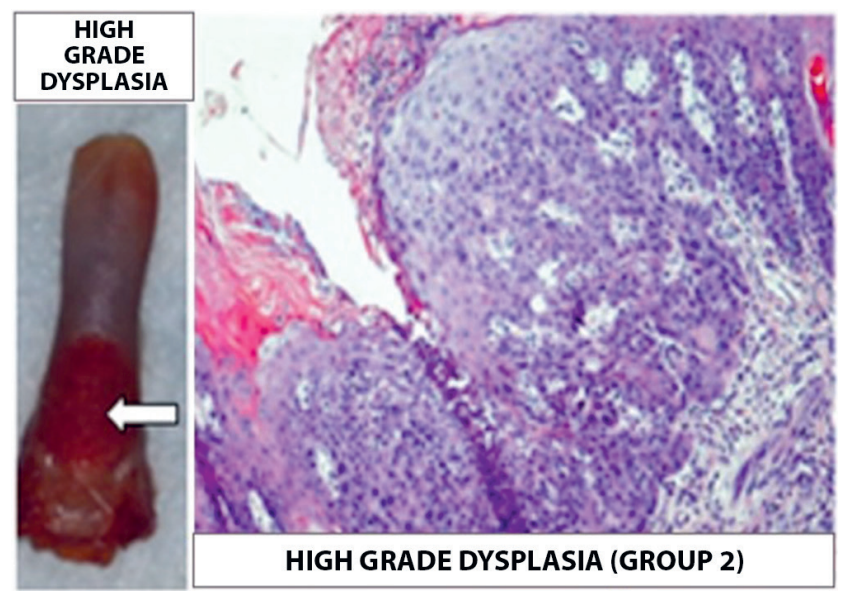

Fig. 2. Macroscopic and histopathological view of group 2 (protection) 


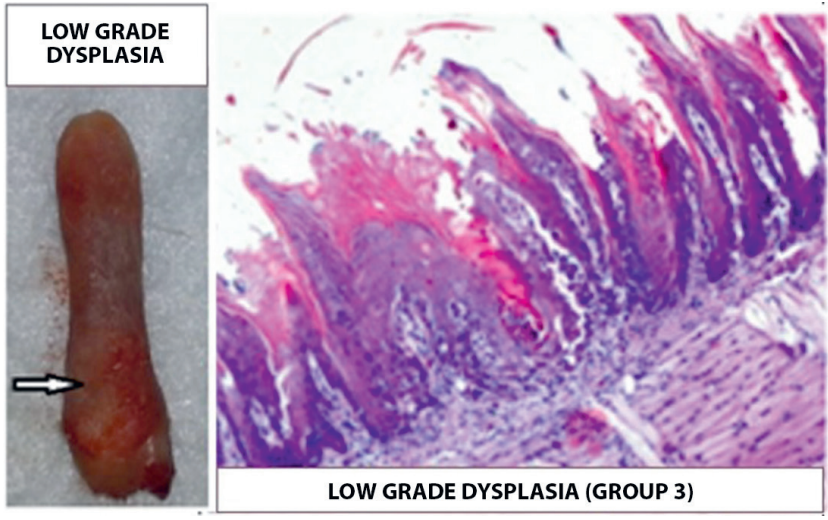

Fig. 3. Macroscopic and histopathological view of group 3 (high-dose therapy)

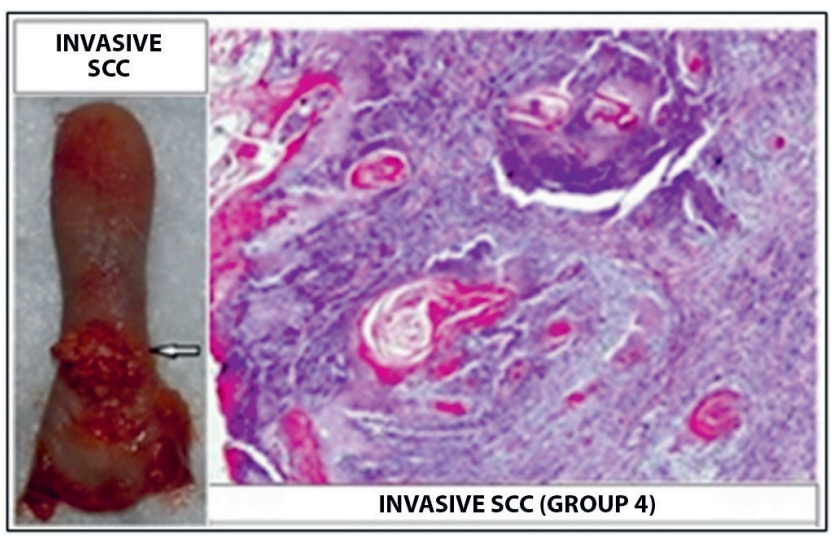

Fig. 4. Macroscopic and histopathological view of group 4 (low-dose therapy)

\section{Biochemical parameters}

The TOS and OSI values in group 3 were significantly lower than in group 1 and group $4(\mathrm{p}<0.01)$ (Table 2$)$. There was no significant difference in the TOS and OSI values between groups 1,2 and 4 ( $\mathrm{p}>0.05$ ) (Table 1). The TAS values in group 3 were significantly higher than in all the other groups $(\mathrm{p}<0.01)$ (Table 2$)$.

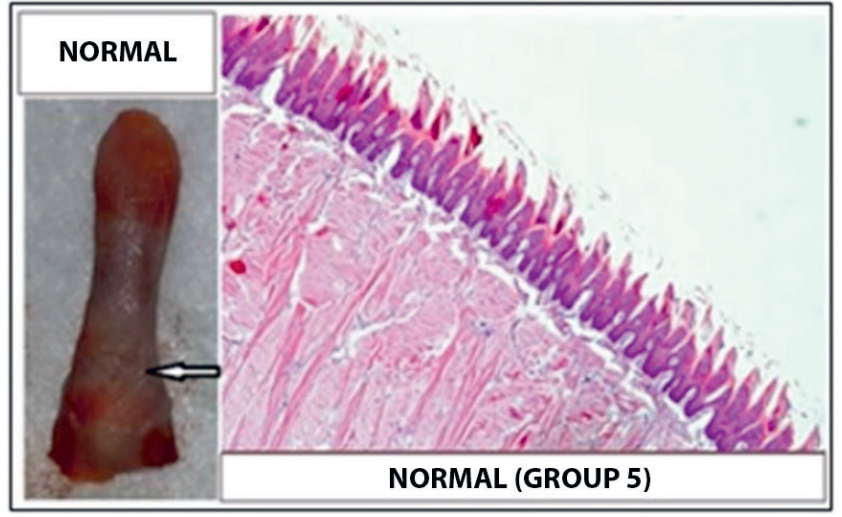

Fig. 5. Macroscopic and histopathological view of group 5 (control)

\section{Discussion}

Oral cavity cancers account for about 3\% of all malignancies. ${ }^{21}$ Squamous cell carcinoma of the tongue is the $2^{\text {nd }}$ most frequent oval cavity cancer. ${ }^{22}$ Smoking, alcohol use and chewing tobacco have been shown to be among the most common causes of tongue cancer. ${ }^{23}$ In $60-$ $70 \%$ of tumors in the oral cavity, diagnosis is made after the tumor has passed the locally advanced stage. ${ }^{24}$ It is thus very important to prevent the spread of the tumor by early diagnosis. Despite advanced treatment methods, during the last decades, the prognosis for patients with oral/ lingual SCC has not improved significantly. ${ }^{25}$

Today, surgery and chemotherapy (CT) are the treatments most frequently used in cases of tongue cancer. However, even though these methods are now the principal modalities for treating tongue cancer, either of them can lead to a number of defective outcomes. For example, surgical treatment creates a great physiological and psychological burden for the patient and can lead to problems with swallowing and speaking, thereby severely reducing the patient's quality of life. Chemotherapy, on the other hand, involves serious toxicity, which may lead to multi-system risks affecting the patient's health. Radiotherapy (RT), even

Table 2. Biochemical parameters (mean \pm standard deviation (SD))

\begin{tabular}{|c|c|c|c|}
\hline Groups & $\begin{array}{c}\text { TOS } \\
{\left[\mu \mathrm{mol} \mathrm{H}_{2} \mathrm{O}_{2} \text { Eqv/L] }\right.}\end{array}$ & $\begin{array}{c}\text { TAS } \\
{[\mu \mathrm{mol} \text { TroloxEqv/L] }}\end{array}$ & $\begin{array}{c}\text { OSI } \\
\text { (TOS/TASX100) }\end{array}$ \\
\hline $\begin{array}{l}\text { Group } 1 \text { (cancer) } \\
\text { (4-NQO) }\end{array}$ & $13.28 \pm 1.07^{b}$ & $1.62 \pm 0.67^{a}$ & $0.081 \pm 0.067^{a}$ \\
\hline $\begin{array}{l}\text { Group } 2 \text { (protective) } \\
\text { (4-NQO+PDTC ( } 300 \text { mg/kg/day), } 12 \text { weeks) }\end{array}$ & $11.93 \pm 1.76$ & $1.48 \pm 0.53^{c}$ & $0.080 \pm 0.037$ \\
\hline $\begin{array}{l}\text { Group } 3 \text { (high-dose treatment) } \\
\text { (4-NQO+PDTC ( } 600 \text { mg/kg/day), } 30 \text { weeks) }\end{array}$ & $7.21 \pm 0.54^{d}$ & $3.14 \pm 0.71^{d, e}$ & $0.022 \pm 0.012^{d}$ \\
\hline $\begin{array}{l}\text { Group } 4 \text { (low-dose treatment) } \\
\text { (4-NQO+PDTC ( } 300 \text { mg/kg/day), } 30 \text { weeks) }\end{array}$ & $12.57 \pm 1.19$ & $1.38 \pm 0.25$ & $0.091 \pm 0.024$ \\
\hline $\begin{array}{l}\text { Group } 5 \text { (control) (saline, } 30 \text { weeks) } \\
\text { One-way ANOVA* (between groups) }\end{array}$ & $\begin{array}{l}5.08 \pm 0.37 \\
p=0.0001\end{array}$ & $\begin{array}{l}1.75 \pm 0.28 \\
p=0.0021\end{array}$ & $\begin{array}{c}0.029 \pm 0.023 \\
p=0.0001\end{array}$ \\
\hline
\end{tabular}

TAS - total anti-oxidant status; TOS - total oxidant status; OSI - oxidative stress index; $¥$ - one-way analysis of variance (ANOVA) test, $\mathrm{p}<0.05$ significance level obtained; ${ }^{a-e} p<0.01$ significance level obtained (Tukey's HSD post hoc test); ${ }^{\text {a }}$ - group 1 compared to group 3; ${ }^{b}-$ group 1 compared to group 4; - group 2 compared to group $3 ;^{d}$ - group 3 compared to group $4 ;{ }^{e}$ - group 3 compared to group 5. 
if advanced technology allows a reduction of the affected area, can cause a number of problems, given the close proximity of several structures in the oropharyngeal region. As a result of these treatment methods, several functions (speaking, mastication, swallowing) can become dysfunctional or distorted. ${ }^{26}$

It is therefore important to repress the carcinogenesis with chemoprotective agents, and many current studies are directed towards identifying currently available ones. ${ }^{4,5}$ Pyrrolidine dithiocarbamate is an NF- $\mathrm{kB}$ inhibitor and is known to be anti-viral, anti-inflammatory, antioxidant and metal-chelating. ${ }^{27}$ It has a strong anti-tumoral effect especially because of NF- $\mathrm{kB}$ inhibition. The NF- $\mathrm{kB}$ mediators produce an anti-apoptotic signal, inhibiting cell apoptosis; thus, the cell loses the normal apoptotic function and, consequently, a tumor can develop. ${ }^{28}$ It has been shown that PDTC induces apoptosis in smooth muscle cells and leukemic cells through an apoptotic pathway. ${ }^{29}$ In addition, it has been shown that tumor cell growth and proliferation in gastrointestinal stromal (GIS) tumors is inhibited thanks to the anti-tumoral effect of PDTC. ${ }^{30}$ In mice, PDTC inhibits tumor formation and reduces tumor angiogenesis in lung cancer through NF-kB inhibition. ${ }^{28}$ Thus, we can expect the NF- $\mathrm{B}$ inhibitor PDTC to be an effective tumor drug, but additional research in this area is required. For this purpose, our study assessed the protective and therapeutic effectiveness of PDTC in carcinoma of the tongue.

In our study, we gave group 14 -NQO (20 ppm) for 12 weeks. According to the literature, 4-NQO is used to generate experimental tongue cancer. Of the 7 rats in group 1 , 4 developed in situ carcinoma, 2 developed high-grade dysplasia and 1 developed middle-grade dysplasia (Fig. 1). These results are consistent with the literature ${ }^{31,32}$ and show that our cancer model was implemented successfully.

Our study also tested whether PDTC in a low dose was effective in preventing the development of cancer. Therefore, we gave group 24-NQO (20 ppm) over 12 weeks along with low-dose PDTC (300 mg/kg/day). After 12 weeks, it could be shown that PDTC inhibits the formation of cancer tissue in rats (Fig. 2). At that time, no significant differences in tumor development could be found between groups 1 and 2 ( $\mathrm{p}>0.05)$. We think that this was due to the low dose administered. Our intention in setting up this group was to assess whether PDTC has protective effects when applied in pre-malignant carcinomas of the tongue.

We planned group 3 to assess the therapeutic effectiveness of PDTC. In this group, after 12 weeks of 4-NOQ administration, we gave high-dose PDTC (600 mg/ kg/day) for the following 18 weeks. At the end of 30 weeks, we found a significant reduction in cancer development in group 3 (Fig. 3). The effectiveness of PDTC applied in high doses in the treatment of tongue tumors was shown macroscopically and histopathologically (Fig. 3). We assume that PDTC produces this effect thanks to its NF- $\mathrm{BB}$ inhibition. In the literature, there are only a few studies showing PDTC to be effective in cancer treatment. ${ }^{28-30}$
In group 4, set up to assess the effectiveness of small doses $(300 \mathrm{mg} / \mathrm{kg} /$ day) of PDTC in cancer treatment, after 30 weeks all the rats had developed cancer (Fig. 4). There was a histological difference between groups 1 and 4, because group 1 was administered 4-NQO for 12 weeks and then was sacrificed, whereas group 4 received low-dose PDTC after 12 weeks of 4-NQO. However, this low dose of PDTC was not effective enough, and cancer development continued.

It is known that oxidative stress plays an important role in carcinogenesis. Reactive oxygen radicals play roles in various places, damaging DNA, interacting with oncogenes, affecting tumor suppressor genes, and affecting immunological mechanisms. ${ }^{33}$

In a study by Doğan et al., oxidative stress parameters were investigated in head and neck tumors. In malignant tumors, TOS values were significantly higher and TAS values lower than in benign tumors. ${ }^{34}$ Various studies have shown a strong antioxidant effect of PDTC. ${ }^{11,12}$ In order to assess oxidative stress, our study evaluated the TAS, TOS and OSI values in intracardiac serum samples taken from all the rats. In group 3, TOS and OSI values were significantly lower than in groups 1 and 4 (Table 2). No significant difference in the TOS and OSI values was found between groups 3 and 5 (Table 2). The TAS values in group 3 were significantly higher than in other groups (Table 2). These data led us to assume that PDTC is a strong antioxidant that can help prevent tongue cancer.

\section{Conclusions}

Our study confirmed a number of general results: 1 ) that 20 ppm of 4-NQO applied over 12 weeks creates experimental tongue cancer in a rat model; 2) that PDTC applied at a dose of $300 \mathrm{mg} / \mathrm{kg} /$ day is not protective against tongue cancer; and 3) that $300 \mathrm{mg} / \mathrm{kg} /$ day of PDTC is not sufficient to stop the progress of tongue cancer. At the same time, our study showed that a dose of $600 \mathrm{mg} / \mathrm{kg} /$ day of PDTC can stop the progress of tongue cancer and lead to a significant reduction of lesions. Our results indicate that the effects of PDTC are achieved by reducing oxidative stress and inhibiting NF-kB.

The limitations of our study include its experimental nature, the lack of comparisons with other non-surgical treatment methods (CT, RT) and the lack of additional groups that would enable evaluation of tumor sizes and survival.

The primary strength of our study is that it investigates the effects of PDTC on tongue cancer for the first time in the literature, providing both histopathological and biochemical evaluation parameters, using different doses of PDTC and evaluating both preventative and therapeutic effects. We have demonstrated experimentally that PDTC can contribute to the prevention and treatment of tongue cancer. This study is the first in the literature on this subject, and additional experimental and clinical studies are needed. 


\section{ORCID iDs}

Aysenur Meric Hafiz (1) https://orcid.org/0000-0002-3066-6255 Remzi Doğan (1) https://orcid.org/0000-0001-5627-1342 Zuhal Gucin (D) https://orcid.org/0000-0001-5330-2158 Omer Faruk Ozer (1) https://orcid.org/0000-0002-1052-8939 Alper Yenigun (1) https://orcid.org/0000-0001-9722-1333 Orhan Ozturan (1) https://orcid.org/0000-0002-6129-8627

\section{References}

1. Balanchaert RH. Epidemiology of oral cancer. In: Ord RA, Balanchaert RH, eds. Oral Cancer. Chicago, IL: Quitessence Publishing; 2000:3-8.

2. Partridge $M$, Emilion G, Pateromichelakis S, Phillips E, Langdon J. Cancerisation of the oral cavity: Comparison of the spectrum of molecular alterations in cases presenting with both dysplastic and malignant lesions. Oral Oncol. 1997;33:332-337.

3. Shklar G. Development of experimental oral carcinogenesis and its impact on current oral cancer research. J Dent Res. 1999:78(12):1768-1772.

4. Kelloff GJ, Crowell JA, Steele VE, et al. Progress in cancer chemoprevention. Ann N Y Acad Sci. 1999;889:1-13.

5. Tanaka T. Chemoprevention of oral carcinogenesis. Eur J Cancer. 1995; 31(1):3-15.

6. Orrenius S. Nobel CSI, van den Dobbelsteen DJ, Burkitt MJ, Slater AF. Dithiocarbamates and the redox regulation of cell death. Biochem Soc Trans. 1996;24(4):1032-1038.

7. Iseki A, Kambe F, Okumura K, et al. Pyrrolidine dithiocarbamate inhibits TNF-a- dependent activation of NF-KB by increasing intracellular copper level in human aortic smooth muscle cells. Biochem Biophys Res Commun. 2000;276(1):88-92.

8. Ross SD, Kron IL, Gangemi JJ, et al. Attenuation of lung reperfusion injury after transplantation using an inhibitor of nuclear factor-KB. Am J Physiol Lung Cell Mol Physiol. 2000;279(3):L528-L536.

9. Schreck R, Meier B, Männel DN, Dröge W, Baeuerle PA. Dithiocarbamates as potent inhibitors of nuclear factor $\mathrm{KB}$ activation in intact cells. J Exp Med. 1992;175(5):1181-1194.

10. Muller DN, Dechend R, Mervaala EMA, et al. NF-kB inhibition ameliorates angiotensin II-induced inflammatory damage in rats. Hypertension. 2000;35(1 Pt 2):193-201.

11. Liu SF, Ye X, Malik AB. Inhibition of NF-KB activation by pyrrolidine dithiocarbamate prevents in vivo expression of proinflammatory genes. Circulation. 1999;100(12):1330-1337.

12. Borrello S, Demple B. NF kappa B-independent transcriptional induction of the human manganous superoxide dismutase gene. Arch Biochem Biophys. 1997;348(2):289-294.

13. Wild AC, Mulcahy RT. Pyrrolidine dithiocarbamate upregulates the expression of the genes encoding the catalytic and regulatory subunits of $\gamma$-glutamylcysteine synthetase and increases intracellular glutathione levels. Biochem J. 1999;338(Pt 3):659-665.

14. Nathens AB, Bitar R, Davreux C, et al. Pyrrolidine dithiocarbamate attenuates endotoxin-induced acute lung injury. Am J Resp Cell Mol Biol. 1997;17(5):608-616.

15. Spiller SE, Logsdon NJ, Deckard LA, Sontheimer H. Inhibition of nuclear factor kappa-B signaling reduces growth in medulloblastoma in vivo. BMC Cancer. 2011;11:136.

16. Yang C, Zhang H, Huang W, Lin Q, Wei H. Effect of combined use of PDTC and paclitaxel on proliferation and invasion of human breast cancer cell line MCF-7 [in Chinese]. Sheng Wu Yi Xue Gong Cheng Xue Za Zhi. 2010;27:1105-1109.
17. Ribeiro D, Kitakawa D, Domingues MA, Cabral LA, Marques ME, Salvadori $D M$. Survivin and nitric oxide inducible synthase production during 4NQO-induced rat tongue carcinogenesis: A possible relationship. Exp Mol Pathol. 2007;83(1):131-137.

18. Erel O. A new automated colorimetric method for measuring total oxidant status. Clin Biochem. 2005;38(12):1103-1111.

19. Erel O. A novel automated method to measure total antioxidant response against potent free radical reactions. Clin Biochem. 2004; 37(2):112-119.

20. Vural M, Camuzcuoglu H, Toy H, Aksoy N. Amniotic fluid prolidase activity and oxidative status in neural tube defects. Fetal Diagn Ther. 2010;28(1):34-39.

21. Kademani D. Oral cancer. Mayo Clin Proc. 2007;82(7):878-887.

22. Bachar G, Hod R, Goldstein DP, et al. Outcome of oral tongue squamous cell carcinoma in patients with and without known risk factors. Oral Oncol. 2011;47(1):45-50.

23. Nagpal JK, Patnaik S, Das BR. Prevalence of high-risk human papilloma virus types and its association with $\mathrm{P} 53$ codon 72 polymorphism in tobacco addicted oral squamous cell carcinoma OSCC patients of Eastern India. Int J Cancer. 2002;97(5):649-653.

24. Lippman SM, Sudbø J, Hong WK. Oral cancer prevention and the evolution of molecular-targeted drug development. J Clin Oncol. 2005; 23(2):346-356.

25. Haddadin KJ, Soutar DS, Webster MHC, Robertson AG, Oliver RJ, MacDonald DG. Natural history and patterns of recurrence of tongue tumors. Br J Plast Surg. 2000;53(4):279-285.

26. Makita H, Mutoh M, Maruyama T. A prostaglandin E2 receptor subtype EP1-selective antagonist, ONO-8711, suppresses 4-nitroquinoline 1-oxide-induced rat tongue carcinogenesis. Carcinogenesis. 2007;28(3):677-684.

27. Ji GQ, Chen RQ, Zheng JX. Macrophage activation by polysaccharides from Atractylodes macrocephala Koidz through the nuclear factor-kB pathway. Pharm Biol. 2015;53(4):512-517.

28. Gao P, Gao YJ, Liang HL. Effect of NF-KB inhibitor PDTC on VEGF and endostatin expression of mice with Lewis lung cancer. Asian Pac J Trop Med. 2015;8(3):220-224.

29. Cheng AC, Huang TC, Lai CS, et al. Pyrrolidine dithiocarbamate inhibition of luteolin-induced apoptosis through upregulated phosphorylation of Akt and caspase-9 in human leukemia HL-60 cells. J Agric Food Chem. 2006;54(12):4215-4221.

30. Panizzi L, Catalano S, Miarelli C, Cioni PL, Campeol E. In vitro antimicrobial activity of extracts and isolated constituents of Geum rivale. Phytother Res. 2000;14(7):561-573.

31. Minicucci EM, Ribeiro DA, da Silva GN, Pardini MI, Montovani JC, Salvadori DM. The role of the TP53 gene during rat tongue carcinogenesis induced by 4-nitroquinoline 1-oxide. Exp Toxicol Pathol. 2011;63(5):483-489.

32. Miranda SR, Noguti J, Carvalho JG, Oshima CT, Ribeiro DA. Oxidative DNA damage is a preliminary step during rat tongue carcinogenesis induced by 4-nitroquinoline 1-oxide. J Mol Histol. 2011;42(2):181-186.

33. Battisti C, Formichi P, Tripodi SA, Vindigni C, Roviello F, Federico A. Vitamin E serum levels and gastric cancer: Results from a cohort of patients in Tuscany, Italy. Cancer Lett. 2000;151(1):15-18.

34. Doğan R, Meriç Hafiz A, Tugrul S, Ozturan O, Keskin S, Kocyigit A. Can oxidative stress parameters be used as biomarkers for the discrimination of malignant head and neck tumors. J Craniofac Surg. 2016;27(3):e316-e320. 